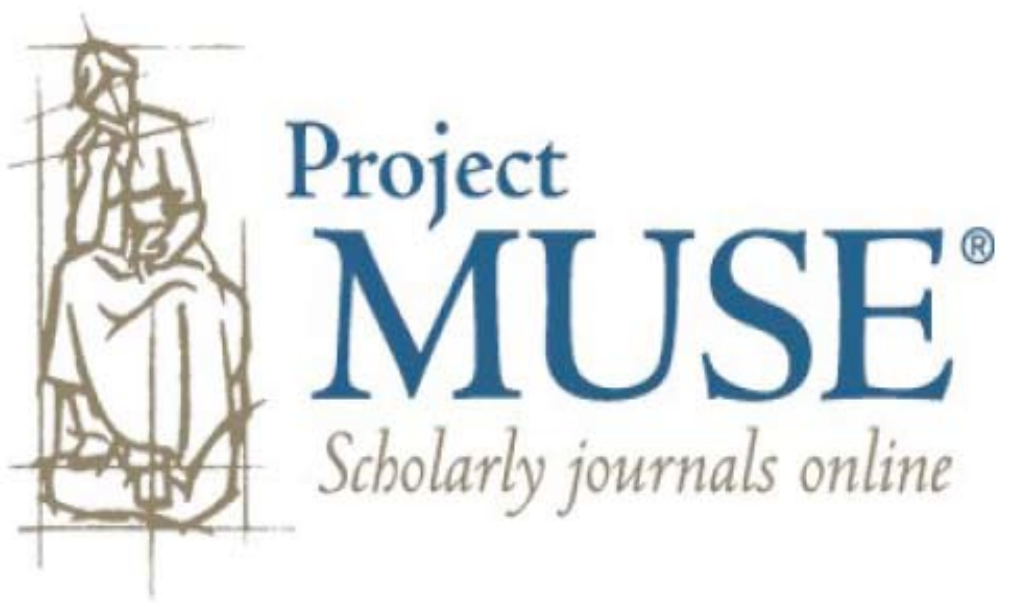




\section{Using Focus Groups to Explore the Stressful Life Events of Black College Men}

\author{
Daphne C. Watkins \\ Jeff Guidry
}

\author{
B. Lee Green \\ Christine Stanley
}

\author{
Patricia Goodson
}

Black students who attend predominately White institutions (PWI) face many obstacles. This study identified the stressful life events of Black college men via focus group discussions and examined how these events impact their mental health and health behaviors. Forty-six participants from a PWI and a historically Black collegeluniversity (HBCU) affirmed that they experience similar encounters with stressful life events, but participants at the PWI reported that their major stressors were the result of "school-related" events, while participants at the HBCU reported stressors that were not school-related. Findings from this study present implications for future health promotion programs that target Black college men.

A February 2005 article in USA Today ("Black men fall behind") reported that from 2000 to 2001, the number of Black men in higher education rose by 30,000. During the same time the number of Black women in college rose by 73,000 suggesting that the gain was twice as large for Black women than Black men. From 2001 to 2002, the increase in the number of degrees (associate's, bachelor's or master's) earned by Black men was less than $3 \%$, whereas the number of Black women earning associate's degrees rose by $6.5 \%$, bachelor's by $4.3 \%$ and master's $4.5 \%$ ("Black men fall behind," 2005). Furthermore, the Justice Policy Institute found that Black men in their early 30 s were nearly twice as likely to have prison records than bachelor's degrees (Western, Schiraldi, \& Ziedenberg, 2003). These figures illustrate that although a number of Black men and women attend college, there is still a disparity between the two groups regarding matriculation and graduation rates. An increasing literature identifies the stressful events of college life as the reason for why more Black men chose to leave college or not attend (Cureton, 2003; Lett \& Wright, 2003; Rowser, 1997). Whether defined in terms of life events or in terms of minor daily hassles, stress has disruptive effects on psychological well-being and functioning and can adversely affect Black college men. In fact, the transition to adulthood for Blacks may be associated with a heightened awareness of restricted opportunities that may lead to increased levels of stress in early adulthood and maladaptive patterns of coping (Williams, 2003).

The cultural, social, and academic experiences of Black undergraduate students at historically Black colleges and universities (HBCUs) and predominately White institutions (PWIs) have been compared by several authors (Bohr,

Daphne C. Watkins is a National Institute of Mental Health Postdoctoral Fellow at the Institute for Social Research at the University of Michigan. B. Lee Green is Executive Director of the Office of Institutional Diversity at the $H$. Lee Moffitt Cancer Center \& Research Institute at the University of South Florida. Patricia Goodson is an Associate Professor in the Department of Health and Kinesiology; Jeff Guidry is an Associate Professor in the Department of Health and Kinesiology; and Christine Stanley is an Associate Professor in the Department of Educational Administration and Human Resource Development and Executive Associate Dean for Faculty Affairs; all in the College of Education and Human Development at Texas A\&M University. 
Pascarella, Nora, \& Terenzini, 1995; Cheatham, Slaney, \& Coleman, 1990; Cokley, 1999; DeSousa \& Kuh, 1996; Fleming, 1984; Flowers \& Pascarella, 1999). For example, early research affirmed that more Black students at HBCUs felt an increased sense of connectedness, power, and affiliation at HBCUs than at PWIs (Fleming). DeSousa and Kuh found that Black students at HBCUs devoted more effort to academic activities; experienced more significant gains in intellectual development, critical thinking, and cultural awareness; and enjoyed greater personal and social benefits than those at PWIs. Likewise, a study by Berger and Milem (2000) found that students who attended HBCUs offered significantly higher self-ratings in three domains of self-concept-psychosocial wellness, academic self-efficacy, and achievement orientation - than Black students attending PWIs. In a more recent study, Harper Carini, Bridges, and Hayek (2004) found that despite their limited financial resources, HBCUs offer better learning environments and support mechanisms for Black undergraduates and greatly influence positive Black student outcomes. In order to gain a better understanding about the experiences of Black college students at HBCUs and PWIs social scientists must understand these experiences in the context of their mental health and health behaviors.

The U.S. Department of Health and Human Services (1999) defines "mental health" as the successful performance of mental function, resulting in productive activities, fulfilling relationships with other people, and the ability to adapt to change and to cope with adversity. Individuals who maintain their mental health find ways to acknowledge and positively cope with the stressors in their lives. Stressors are demands made by the internal or external environment that upset balance or homeostasis, thus affecting physical and psychological well-being and requiring action to restore balance or equilibrium (Lazarus \& Cohen, 1977). During the 1960s and 1970s the focus of research on stress shifted to identifying and quantifying potential stressors, or stressful life events. Also during that era, stress was viewed as a transactional phenomenon that relied on the meaning of the stimulus to the perceiver (Antonovsky, 1979; Lazarus, 1966). The understanding of stress during that time involved the perceptions of the events (rather than the events themselves) as the main determinants of effects on subsequent behaviors and on health status. Stressful life experiences are interpreted as transactions between the person and the environment in which the impact of external stressors is dependent upon the person's appraisal of that stressor (Lazarus \& Cohen).

In the present study focus group discussions were used as a first step in gathering information about the mental health of Black college men. Two research questions were considered in this study: (a) What are the stressful life events of Black college men? and (b) How do these stressful events contribute to their mental health and health behaviors? Our formative research plan demonstrated a theoretical and methodological focus on complex relations between (a) personal and social meanings, (b) individual and cultural practices, and (c) the material environment or context (Ulin, Robinson, \& Tolley, 2005). Michael Crotty (1998) affirmed that the theoretical perspective is the "stance lying behind the methodology" (p. 66), which gives meaning to the design's choice of methods, logic and components.

\section{METHODS}

\section{Study Design}

Focus groups can provide detailed insights into a target audience's perceptions and motivations (Ulin et al., 2005). They can also capture the 
complexities of the thinking and behavior of a target audience in greater depth than a quantitative survey. Group interaction and dynamics can help elicit in-depth thought and discussion as well as brainstorming, because participants can build off one another's ideas. Also focus group questions can be modified as information needs change and barring unexpected recruitment difficulties, focus groups can be coordinated, conducted, and analyzed within a relatively short period of time (Ulin et al.). Prior to the focus group discussions, a trained facilitator reviewed the goals of the study and consent forms with participants. The facilitator was a Black female doctoral student from the PWI. Questions from the focus group protocol were administered to the participants at each campus. Discussions lasted approximately 90 minutes and were audiotape recorded, transcribed verbatim, and analyzed using computer software. Although the questions were organized into five sections(a) health behavior, (b) general mental health, (c) comfort with discussion of mental health, (d) individual mental health, and (e) mental health management-this study reports the results from questions asked during the individual mental health and mental health management sections of the focus group protocol.

\section{Participants}

All English-speaking Black college men who attended the HBCU and the PWI during the 2005-2006 school year were eligible to participate in the study. Both institutions were located in the southern region of the United States, centrally located approximately equidistant from three large metropolitan cities. Enrollment at the HBCU was approximately 10,000 students, and the PWI's enrollment was over 40,000 students. The investigator recruited men at the PWI and solicited the help of a faculty member to recruit the men at the HBCU. Participants at each institution were recruited via email, direct person-toperson, and "snowball sampling." Snowball sampling is the process of asking people who have already been recruited for names of other potential participants (Morgan \& Krueger, 1998). An honorarium was offered to all participants in the study.

\section{Data Analysis}

Transcription. All focus group discussions were transcribed verbatim - three were transcribed by a local transcription service and two were transcribed by the focus group facilitator. Transcriptions occurred between October 2005 and December 2005. Each 1-hour focus group discussion took an average of 7 hours to transcribe. After transcriptions were completed the data were entered into computer software for data reduction and analysis.

Content Analysis. Content analysis is a "quantitatively oriented technique by which standardized measurements are applied to metrically defined units and are used to characterize and compare documents" (Manning \& Cullum-Swan, 1994, p.464). Microsoft ${ }^{\circledR}$ Excel was used to manage and organize the focus group data from this study (Stockdale, 2002; Swallow, Newton, \& Lottum, 2003); however, all of the features are available on other commercially available software programs such as NUD*IST and Nvivo. Microsoft ${ }^{\circledR}$ Excel facilitates content analysis allowing text data to be categorized and indexed via the spreadsheet and charting options. Two primary goals of focus group analyses were to (a) reveal the important themes and their degree of emphasis that underlie participants' comments with regard to the study questions, and (b) to compare these themes across different groups (Stockdale). From the five focus groups conducted, we created a taxonomy that organized stressful life events and the ways in which they impact mental health. A "member 
TABLE 1.

\section{Participant Demographics (Black College Men)}

\begin{tabular}{lcc}
\hline & $\begin{array}{c}\text { PWI } \\
(\boldsymbol{n}=\mathbf{2 2})\end{array}$ & $\begin{array}{c}\text { HBCU } \\
(\boldsymbol{n}=\mathbf{2 4})\end{array}$ \\
\hline Undergraduate & 12 & 24 \\
Graduate & 10 & 0 \\
Member of a fraternity & 10 & 1 \\
Participates in extracurricular & 17 & 14 \\
activities & 3 & 5 \\
Student-athlete & & \\
\hline
\end{tabular}

check" as described by Morgan and Krueger (1998) was also implemented to ensure researcher neutrality. This technique required providing focus group participants with a summary of the discussion so that they could make certain that their views and opinions were accurately represented. The outcome of the member checks indicated that the facilitator had accurately depicted participant responses.

Focus group data were analyzed using multiple methods as suggested by Morgan and Krueger (1998): transcript-based analysis, tape-based analysis, note-based analysis, and memory-based analysis. For this study, transcript-based analysis was conducted using a written report (based on the complete transcript) with some use of field notes and the facilitator debriefing notes. Tape-based analysis involved analyzing an abridged transcript with field notes and the facilitator debriefing notes. For the note-based analysis the facilitator analyzed the focus group data based on summary comments, selective tape reviews, and field notes. Memory-based analysis required the facilitator to analyze data based on memory and prior experiences of the participants.

\section{RESULTS}

There were a total of 46 focus group participants in this study whose ages ranged from 18 to 26. Participants were Black college men who attended either a HBCU $(n=24)$ or a PWI $(n=22)$ during the 2005-2006 school year. All participants at the HBCU were undergraduate students ( 1 member of a fraternity, 14 who were involved in other on- and offcampus extracurricular activities, and 5 student-athletes), however participants at the PWI included 10 graduate students and 12 undergraduate students $(10$ members of a fraternity, 17 who were involved in other onand off-campus extracurricular activities, and 3 student-athletes; Table 1). Participants represented students from all academic disciplines (e.g., psychology, business, kinesiology, political science, etc.) and classifications (i.e., freshmen, sophomore, junior, senior, master's, and doctoral).

Nineteen themes (Table 2) emerged from the focus group discussions. The theoretical propositions that led the study were used to assist in interpreting the categories and the findings. Based on the two questions considered in this study-(a) What are the stressful life events of Black college men? and (b) How do these stressful events contribute to their mental health and health behaviors? - a taxonomy was created to interpret the themes and systematize their frequency at each institution. Trends amid the most prevalent themes were apparent at each institution. Discussions at the PWI were dominated by conversations about acceptance, or "fitting in"; cultural conflict; racism/discrimination; social support; and (overall) stressors. Meanwhile, focus group participants at the HBCU focused their discussions heavily on their image, their lack of resources for advancement, and (overall) stressors. 
Participants at both institutions emphasized that the strategies they use to assess their problems and to cope with their stress are modeled after their family members, mainly their mothers and/or fathers. From this discussion, the topic of socialization as a survival technique for Black men emerged. To this, participants at the PWI expressed the importance of socialization at their institution, whereas those at the HBCU emphasized their need for socialization as a means of survival in America. The aforementioned topics were used to extrapolate the stressful life events of Black college men in this study as well as to assess how these events contribute to their mental health and health behaviors. Below, each research question is examined further.

Stressful Life Events. One question posed during the discussion about stressful life events was, "What kind of things lead to stress in your life?" Responses from participants at the PWI included: "White America," being accepted, the legacy of slavery, money, classes, and knowing how much 'weight' is put on Black men to succeed. Similarly, participants at the $\mathrm{HBCU}$ responded to this question by highlighting the major role that society plays in many of their decisions:

The number one stress I got is "just don't it up." Some of it comes from your

family, some of it comes from you, some of it comes from society. Society already has this stigma that Black men ain't and so you don't want to be that. You don't want to have had the opportunity to be something and then fall off and become a stereotype.

Although participants at the PWI affirmed that being accepted in "White America" is stressful; participants at the HBCU agreed with one of their peers who recognized social and societal choices as the major stressor in his life:

One of the biggest stresses that I have is do I go out there and chase my dreams or do I take what society gives me? I can just go to college get a degree and then get a job, but then again will I truly be happy? Or should I take that risk to get out there and do the things that I truly want to do and try to become who I want to become. That stresses me out because I know so many Black people before me have tried to get somewhere and they didn't succeed. Plus I know many people who didn't have

TABLE 2.

Frequency of Focus Group Discussion Themes Based on Responses from Each University a

\begin{tabular}{lcc}
\hline Theme & PWI & HBCU \\
\hline Acceptance/"fitting in" & 4 & 1 \\
Church/God & 2 & 2 \\
Coping mechanisms (+/-) & 2 & 2 \\
Cultural conflict & 4 & 2 \\
Health behaviors and education & 2 & 2 \\
Help-seeking & 2 & 1 \\
Image (how society views & & \\
Black men) & 2 & 4 \\
Lack of resources for & & \\
advancement & 1 & 4 \\
Learned behavior (mother/father) & 3 & 3 \\
Media expression of Black men & 1 & 1 \\
Mistrust of institution(s) & 3 & 1 \\
Racism/discrimination & 4 & 1 \\
Reality/realization of & & \\
irreversible stress & 2 & 2 \\
Responsibility/roles as & & \\
Black men & 2 & 2 \\
Self-concealment & 2 & 2 \\
Socialization (or acquiring & & \\
culture) & 3 & 3 \\
Social support & 4 & 1 \\
Stigma & 2 & 3 \\
Stress/stressors & 4 & 4 \\
\hline
\end{tabular}

a Frequency Codes: 1 = Mentioned; 2 = Mentioned frequently; 3 = Mentioned very frequently; 4 = Dominated discussions. 
a chance to get a college degree and now they are trying to be entrepreneurs and they are just barely making it.

Other stressors that the men at the HBCU experienced were running businesses, being student-athletes, taking care of nuclear and extended family members, balancing life, being role models for family members (first generation college students), money, grades, women, bills, and the pressure of deciding whether to stay in school or leave school and "hustle," or make other efforts (not school-related) to earn money.

When asked about the stressors of college life, participants at the PWI and the HBCU provided similar responses. At the PWI, participants said that simply being a student in undergraduate/graduate school was stressful. Focus group participants also spent a substantial amount of time discussing a topic that was not discussed at the HBCU: racism. Clark, Anderson, Clark and Williams (1999) defined racism as "beliefs, attitudes, institutional arrangements, and acts that tend to denigrate individuals or groups because of phenotypic characteristics or ethnic group affiliation" (p. 805). At the PWI, members provided personal narratives about their experiences with racism:

\section{Participant X:}

Within the first three months of me being up here, I experienced five different racial experiences ... that just really stressed me out. I'm here just trying to get my education, didn't bother nobody, wasn't doing anything wrong but I was just suspected of doing something wrong. That just really, you know, just caused me to just want to be mean, and just be hurtful, get in my all black [attire] and walk around with that build and just eye people, you know. It just made me think that they don't want me to be here so why don't I just turn that around [and say],
"You don't want me to be here"-that's going to make me push even harder to excel at what I got to do.

Participant Y:

Everywhere I go in [the city], especially the other places in [the state], my Blackness is always a factor. At [this institution] I've experienced some racism off campus by people in the community, but the thing that distresses me at [this institution] is that people, even professors, really don't know how to deal [with] or know what things a Black person goes through, because we don't have a lot of Blacks here.

\section{Participant Z:}

After being here for almost seven years now, I didn't realize how much of an affect it was having on me. I had a lot of friends from New York, Pennsylvania, California and other places and they were really surprised at a lot of things [that I encounter]. This led me to believe that I had become so accustom to being abused. It's like if I was beat from day one when I was born, I'm used to being beat. And so I kind of sense that being at [the institution], in a lot of ways, it makes you accustomed to getting beat. And so we get used to being treated badly and to me that's more dangerous than anything. You think, "I deserve to be beat." So you know, you expect that kind of treatment everywhere you go and you act in a real docile manner, and you're not willing to maybe sit up and claim those things that you'd like to be yours ... that happens subconsciously.

During the discussion about racism and discrimination, Participant $\mathrm{Z}$ provided his perspective about institutional racism as a Black man on the campus of a PWI:

Participant Z:

I would rather somebody call me a nigger ... than experience institutionalized 
racism. It's indirect. It's the silent killer. You know, it's like, even going for job interviews, you hand them your resume when you walk through the door, you know, you say, "I wonder if they knew I was Black?" And that kind of stuff it makes you kind of anxious.

Not only did the men recognize racism as a major stressor at the PWI, but they also discussed their internal struggle with not acting "too White" or "too Black," an issue that, unlike their peers at HBCUs, they admittedly face everyday:

\section{Participant A:}

The whole "what's too White and what's too Black" is really just a stereotype of what Black people have on Black people and White people have on White people. You get most of the comments from people from your own race. Do you know what I'm saying? I'll admit I did it before myself.

\section{Participant B:}

I think we think about these things too much, I always ask the question, "What is Black?" I mean, there's no real textbook definition of what Black is. You know, we've got history but we don't go to that to talk about what's Black. We go to what's on TV, what's on BET, MTV, VH1. We go to a lot of media avenues to talk about what's Black ... I mean if you don't know that stuff, "Well, you're not Black enough." And so when a White person comes and learns all that, they're Blacker than you are! You know, but being Black has nothing to do with any of that.

In addition to being faced with the daily hassles that cause stress in their lives, the men are also challenged to cope with psychosocial stressors, which impacts their emotional and psychological health. Participant $\mathrm{Z}$ provided thoughts on the realization that he faced regarding the internal battle that Black men endure compared to the "average" person, or individuals who are not Black and male:

The fact that [Black men] have to go into so much processing to try to figure out the different dynamics and different perceptions kind of let's me know that I'm dealing with a lot more psychological pressure and stress than the average person would be.

Mental Health and Health Behaviors. The purpose of the health behaviors section of the focus group protocol was to understand the health and health behaviors of Black college men and how these behaviors are influenced by their mental health. Black college men at each campus were posed questions regarding their health and health behaviors. Focus group participants were asked to talk about the role that mental health plays in their lives. To this, participants at both institutions replied that mental health does not play a role in their lives. The men at the PWI stated that they do not let their mental health "get to that point." According to them, "what has happened, has happened" and they always "move on." In the same way, men at the HBCU stated that they do not let their problems get to the point where they begin to have an effect on their mental health. Here, the men held firm to their belief that Black people do not stress over "minor" things like people of other races and cultures. "Stress for Black people is over survival."

It was noted that trying to eat healthy, prioritizing, and stress all affected the men's health practices. Similar to college students of all racial/ethnic groups (Ross, Niebling, \& Heckert, 1999), the men in this study tend to eat differently and have unfavorable sleeping habits during their college years. Participants at the PWI discussed their efforts to exercise more and their failure to do so. The men at each campus affirmed that sacrificing sleep to get "a good grade or a good GPA" is typical 
for all college students, not just Black men. Moreover, poor eating habits were considered a sign of a busy student and had the potential to improve over time. A student at the PWI admitted:

I used to eat anything I wanted. . . . and then just play like three hours of pick-up basketball games, probably every other day ... then when I came to grad school, then everyone looked down on me for eating McDonalds, or eating fast food. So it's a lot of peer pressure to eat healthy and so then I became very healthy and exercised.

Another participant in the group compared his health behaviors before he came to college to his current behaviors:

I used to get full course meals ... every part of the food group, used to work out all the time, and I played sports and stuff. ... When I was at home I cooked, so I mean, my parents right now really don't influence it; it's just that I don't have the resources to cook. Like when I go off campus, I will. I don't mind eating healthy, it's just that I have a microwave and there's only so much you can cook in a microwave.

There were many similarities between participants at the PWI and at the HBCU regarding health behaviors. At the HBCU, participants stated that they were not able to afford to eat fruits and vegetables. Others said that they did not have time to eat healthy, because "most quick meals are fast food," and another participant highlighted the influence of money on his eating habits by saying, "I eat one time a day everyday because I gotta pay bills." A student in this discussion asserted that due to physical appearance, Black people want to eat healthy, but they cannot because they lack the resources to do so:

I feel like Black people, we would be healthier than the others if we had the resources. ... Black people have pride in everything that we do so we will be healthy because we want to look good. And I feel like that's every Black person.

Participants at the HBCU noted that their health practices are influenced by their classes, the opposite sex, and bills, and they sometimes become so "stressed out" that they do not eat or sleep_-oftentimes turning to alcohol to help with rest: "I'm going to be honest. When I don't sleep, I drink to catch up on sleep." Participants at the PWI admitted to their poor health practices, but justified their behaviors by acknowledging that they practice poor health habits because they are in college and they have "no choice." They affirmed that when college is over they will engage in better health habits:

For right now I think anybody in school, for the most part, will be learning about themselves a lot. I know I learned a lot about myself during these-going into my fifth year here. Eventually I'm gonna have to get to the point where I'm gonna have to be stable again . . . but that's all going to take place after I "get paid."

Although managing busy lifestyles results in poor health choices, the men from this study acknowledged that their mental health (or lack thereof) does significantly impact their health behaviors. Men at the HBCU admitted to confining themselves to their dormitory rooms when they feel depressed, which strongly influences their eating habits (i.e., only having access to a microwave) and physical activity. Participants at the PWI admitted to not eating healthy, drinking alcohol when stressed out, cooking meals in a microwave oven frequently, not cooking/eating vegetables, having sporadic eating habits, and not wanting to cook because they did not enjoy it. Men at the HBCU acknowledged the strong association between money and healthy eating. "Without money," 
one announced, "we can't eat healthy foods." Like men at the PWI, many of the men at the HBCU confessed to doing much of their "cooking" with the microwave oven, as it is one of the few appliances that they are allowed to have in their dormitories. Not only do the men eat fast food, but they are content with this behavior because oftentimes, they are just happy to eat.

In college, you're constantly on the go so you don't have time to rest, you don't have time to go and get something healthy to eat. You gotta move. A lot of times, you don't have time to sleep. You don't have time to be worried about your health 'cause you worried about passing this class, paying these bills.

During their discussion about health behaviors, the men at the HBCU also spoke about their desire for more health education. They identified their need more information on illnesses and disorders that they would not otherwise consider major health problems, as well as their need for health education on signs and symptoms of depression and anxiety. According to one participant:

People can have a complex about themselves and they can think that that's just how they are supposed to be because that's all they've known themselves to be . . . you might not know it because your whole life you've been having mental health problems but all you knew was your mental health problem. ... It's like, educationbased. You might have something and you don't even know that you have it because you don't know anything about it.

Participants at both the PWI and the HBCU agreed that their college years are a stressful period. The men identified specific events that cause stress in their lives, often defining their stress in terms of daily hassles. The daily hassles of the Black college men in this study presented challenges that directly influenced their poor health habits.

\section{DISCUSSION}

This study sought to identify the stressful life events of Black college men and how these events influence their mental health and health behaviors. The authors are not aware of prior research that address these concerns with Black college male populations; therefore, this study may be the first of its kind to inquire about the mental health of Black college men and examine how this shapes their health behaviors. The Black college men in this study experienced stressful life events and encountered stressors similar to those of most college students, such as money, classes, and the opposite sex (Ross et al., 1999). Unlike the Black men at the HBCU, however, men at the PWI experienced a plethora of school-related stressors. Discussion topics at the PWI included racism and the plight of being a Black male student at a PWI. For example, participants indicated that "carrying the weight of other Black students," "not falling into the stereotype," and "not acting 'too White' or 'too Black" were major concerns that lead to stress in their lives. These findings were consistent with those of Thompson Neville, Weathers, Poston, and Atkinson (1990) who found that Black college students are more likely than White students to think that they are being singled out for differential and inferior treatment. This was also reiterated by June, Curry, and Gear (1990) who reported that predominately White colleges have failed to combat Black students' perceptions of classroom biases, hostile interpersonal climates, and feelings of social isolation. Such findings demonstrate a strong need for university officials to re-evaluate their approaches used to support Black college men; approaches that 
may be the result of their feelings of deception and mistrust of the university community.

Black college men at the PWI embraced their daily stressors as influenced primarily by their school-related interactions, specifically racism. Walden (1994) highlighted the effects of racism on Black college students and found that racism plays a significant role in social and mental health. Black men from the PWI reported racism as a major stressor; however, study participants appeared to confront this challenge by learning to adapt to their environments and by providing social support for one another. A discussion at the PWI about what it means to be Black led to apprehension regarding acceptance, social support, and selfconcealment as experienced by Black men on a predominately White campus. In order to tackle these hardships, June and colleagues (1990) suggested that postsecondary institutions recognize the patterns of how Black students use campus services and devise strategies to help them at points of entry; encourage students to develop and maintain strong liaison relationships with key offices on campus; and provide appropriate training for residence hall, health center, academic advising, and financial aid personnel about dealing with Black students. Assisting staff in understanding how racism and feelings of alienation and isolation are processed by Black college men may help alleviate the severance between these students and campus professionals.

Focus group participants at the $\mathrm{HBCU}$ shared stressors similar to those of their peers at the PWI (i.e., money, bills, the opposite sex, school); however, participants at the $\mathrm{HBCU}$ indicated that their major stressors are usually not affiliated with school or "college life." Participants affirmed that their stress comes from having to support family members (nuclear and extended) and balancing a life that involves academia but is also dominated by managing their own private businesses, or "hustles." Moreover, men at the HBCU discussed their struggle with the decision to stay in school or quit school so they can devote more time to their hustles. The discussions focused on their challenges with trying to "do the school thing" and trying to make money on the side by cutting hair, doing yard work, working two or more jobs, "making" music, and participating in other entrepreneurial endeavors. During the discussion, one focus group participant from the HBCU posed a rhetorical question: "Do I chase my dreams or do I take what society gives me?” Interestingly, the other participants revealed that they also struggle with this question. These findings draw attention to the life choices of Black college men who attend HBCUs and those who attend PWIs. One assumption may be that Black men at the HBCU have a unique perception regarding the influence of external variables on their academic lives and as a result they arrange their lives so that if one endeavor is unsuccessful, they have other options already in place. In the present study, men from the HBCU preferred to focus on numerous projects at once, in case one project is unsuccessful, while men at the PWI chose to focus their attention on one or two activities within its context, oftentimes school and another activity (e.g., school and job; school and fraternity; school and athletics).

Not only were Black men at both institutions concerned about their stressful life events, but they were also adamant about discussing their coping mechanisms. At both the HBCU and the PWI, participants affirmed that they cannot (and do not) devote time to worrying about their stressors because they have developed a philosophy driven by their commitment to doing whatever it takes to be successful. According to these men, their tasks must be accomplished, so they continue to work hard despite the challenges they might face. Knowledgeable about the destructive 
image that society has shaped about Black men, study participants at both institutions indicated that their stoicism and determination to proceed against all odds derived from their families, specifically parents and grandparents. Social scientists should consider the potential for future research involving the stoicism of Black college students. Interestingly, stoicism was also identified by Baker (2001) as one of the three alternative expressions of depression in Blacks (the other two were "the angry, evil one with a personality change" and "the John Henry doer"). Findings from this study are aligned with those of Black Americans and high-effort coping (Bennett et al., 2004; Ford, Hill, Butler, \& Havstad, 2001) and have implications for future work conducted with the "John Henryism hypothesis" (James, Hartnett, \& Kalsbeek, 1983)—a strong behavioral predisposition to cope actively with psychosocial environmental stressors-and Black college men.

Aside from the stressful life events of Black college men, this study also investigated the probable effect that mental health has on health behaviors. Although men from this study reported that mental health does have an impact on their health behaviors (i.e., drinking when stressed, sporadic eating habits when experiencing anxiety, and a lack of physical activity when depressed), when participants were asked to discuss the role that mental health plays in their lives, men at both campuses affirmed that mental health does not play a role in their lives. This response may be due to the participants' skewed understanding of mental health terminology and the stigma associated with mental health and illness in the Black community (Snowden, 2001). Future efforts should be devoted to the effects of stigma on Black college students and how stigma influences their health and health behaviors.

Also noteworthy in this study were the men's desire for more health education so that they are able to identify problems at earlier stages. Results imply that the Black college men from this study would like more information about mental and physical health made available to them. Participants also disclosed that they would consider seeking help if they believed they needed it; however, they are not provided with the health education to recognize when they or their peers are in need of professional help. Instead, they affirmed that their behaviors are modeled after their family members who have proudly embraced lifestyles that lessen the need of health professionals. Study participants also questioned the signs and symptoms of mental disorders as experienced by Black men, a discussion that evokes the relevance of previous studies that examined alternative expressions of depression in Black adults (Ayalon \& Young, 2003; Baker, 2001; Baker, Espino, Robinson, \& Stewart, 1993; Myers, 1993). Social scientists should also deem this an important topic to be explored in future studies.

Culturally appropriate, gender-specific health promotion and disease prevention interventions are needed for Black men (Davis, 1999), especially Black men on college campuses. Due to the risks associated with health and well-being, and the complex interrelationship between multi-factorial factors, multidisciplinary interventions designed to address the dynamic intersection of these various health determinants are especially needed (Courtenay, 2000). Courtenay (2003) noted in a recent study that the development of these interdisciplinary methods to study men's health will require addressing the various health determinants involved and the disciplinary differences in outcome measures, population studies, methodologies applied, and rigor of intervention evaluation. These requirements will be particularly relevant for future work with Black college men. 
In general, men (including college men) are less likely than women to seek health care (Courtenay, 1998, 2000). Therefore any encounter a health professional has with a college man may be the only opportunity for assessment and intervention that any health professional will have with that man for a long time (Courtenay, 2004). This places college health professionals in a unique position to impact the lives of Black college men during a very influential time in their development. Literature suggests that people are more likely to be helped to prevent future disease by health professionals who ask, educate, and counsel them about personal health behaviors than by those who perform physical examinations or tests (Courtenay, 2001), which again places college health professionals in a unique position. If Black college men are offered information and services that they believe will benefit their personal growth, then they are more likely to embrace those services. By establishing relationships with Black college men and encouraging them to build rapport with college health staff, the gateway to positively influencing their mental health and health behaviors can be channeled through a strong and supportive environment.

A dearth of literature considers Black student health and health behaviors, and an even smaller number of studies contemplate the health of Black male students. As a result of this knowledge gap, there is a need for more research on Black college men's health and health behaviors. Although there appears to be several studies that address the academic, cultural, and social gains of Black students who attend $\mathrm{HBCUs}$ versus those who attend PWIs (Bohr et al., 1995; Cheatham et al., 1990; Cokley, 1999; DeSousa \& Kuh, 1996; Fleming, 1984; Flowers \& Pascarella, 1999), there is sparse literature about the health and health behaviors of Black college men. This paper serves as a first step to understanding the stress of Black college men and can also provide a foundation on which future research endeavors are constructed. Future studies should continue to investigate the mental health and health behaviors of Black students who attend HBCUs and PWIs and should consider the utility of more culturally appropriate, gender specific measures in research conducted with Black college students. Although the results from this study are valuable in that they provide insight regarding the stressful life events of Black college men, there are a couple of limitations. First, the majority of the participants at the HBCU were psychology majors, so some participants may have been more familiar with psychological terminology than others. Second, the prevalence of mental health/mental illness stigma in the Black community overall may have resulted in participants' limited willingness to disclose information in a group setting. The results from this study should be considered a valuable contribution to the body of literature apart from its limitations.

\section{CONCLUSIONS}

The health of Black college men can serve as an indicator for the overall health of Black Americans. This study sought to investigate the health and health behaviors of Black college men and found that there are no major differences in the health of the men who attended the PWI and those who attended the HBCU in this study. Regarding stressful life events experienced by these Black college men, however, racism and other school-related variables were identified as major stressors for men at the PWI, whereas non-school-related events were identified as stressors for men at the HBCU. This information can be used by program planners to create more health promotion programs that target Black college men. One of the ways to improve the health 
of Black men is to address their health and health behaviors early, and for some Black men, many health issues can be addressed during their college years. The steps taken toward the improvement of health in populations of Black college men will not only influence their years in college, but will also have a positive impact on their roles as partners and fathers.

Correspondence concerning this article should be addressed to Daphne C. Watkins, Ph.D., Research Fellow, 1080 South University, Suite B660-32, Ann Arbor, MI 48109-1106; daphnew@umich.edu

\section{REFERENCES}

Antonovsky, A. (1979). Health, stress, and coping. San Francisco: Jossey-Bass [reprint 1991].

Ayalon, L., \& Young, M.A. (2003). A comparison of depressive symptoms in African Americans and Caucasian Americans. Journal of Cross-Cultural Psychology, 34(1), 111-124.

Baker, F.M., Espino, D.V., Robinson, B.H., \& Stewart, B.S. (1993). Assessing depressive symptoms in African American and Mexican American elders. Clinical Gerontologist, 14(1), 15-29.

Baker, F. M. (2001). Diagnosing depression in African Americans, Community Mental Health Journal, 37(1) 31-38.

Bennett, G., Merritt M., Sollers, J. J., Edwards, C., Whitfield, K. E., Brandon, D. T., et al. (2004). Stress, coping, and health outcomes among African Americans: A review of the John Henryism hypothesis. Psychology and Health, 19(3), 369-383.

Berger, J. B. \& Milem, J. F. (2000). Exploring the impact of historically Black colleges in promoting the development of undergraduates' self-concept. Journal of College Student Development, 33, 203-213.

Black men fall behind. (2005, February 15). USA Today, p. 10A. Retrieved February 22, 2005, from http://www.usatoday. com/printedition/news/20050216/edtwo16.art.htm

Bohr, L., Pascarella, E. T., Nora, A., \& Terenzini, P. T. (1995). Do Black students learn more at historically Black or predominately White colleges? Journal of College Student Development, 36, 75-85.

Cheatham, H. E., Slaney, R. B., \& Coleman, N. C. (1990). Institutional effects on the psychosocial development of African-American college students. Journal of Higher Education, 70(2), 134-202.
Clark, R., Anderson, N.B., Clark,V.R., Williams, D.R. (1999). Racism as a Stressor for African Americans: A Biopsychosocial Model. American Psychologist, 54, 805-816.

Cokley, K. (1999). Reconceptualizing the impact of college racial composition on African American students' racial identity. Journal of College Student Development, 40, 235-246.

Courtenay, W. H. (1998). College men's health: An overview and a call to action. Journal of American College Health, 46(6), 279-290.

Courtenay, W. H. (2000). Teaming up for the new men's health movement. Journal of Men's Studies, 8(3), 387-392.

Courtenay, W. H. (2001). Counseling men in medical settings. In G. R. Brooks \& G. E. Good (Eds.), The new handbook of psychotherapy and counseling with men: A comprehensive guide to settings, problems, and treatment approaches (Vol. 1, pp. 59-91). San Francisco: Jossey-Bass.

Courtenay, W. H. (2003). Key determinants of the health and well-being of men and boys. International Journal of Men's Health, 2(1), 1-30.

Courtenay, W. H. (2004). Making health manly: Social marketing and men's health. Journal of Men's Health \& Gender, 1(2-3), 275-276.

Crotty, M. (1998). The foundations of social research: Meaning and perspective in the research process. Thousand Oaks, CA: Sage.

Cureton, S.R. (2003). Race-specific college student experiences on a predominately White campus. Journal of Black Studies, 33(3), 295-311.

Davis, L. E. (Ed.). (1999). Working with African American males: A guide to practice. Thousand Oaks, CA: Sage. 
DeSousa, D .J., \& Kuh, G. D. (1996). Does institutional racial composition make a difference in what Black students gain from college? Journal of College Student Development, 37, 257-267.

Fleming, J. (1984). Blacks in college: A comparative study of students'success in Black and White institutions. San Francisco: Jossey-Bass.

Flowers, L., \& Pascarella, E. T. (1999). Does college racial composition influence the opened to diversity of African American students? Journal of College Student Development, 40, 377-389.

Ford, M .E., Hill, D., Butler, A., \& Havstad, S. (2001). Applying health locus of control and John Henryism Active Coping theories to older African American adults. Journal of Mental Health and Aging, 7(1), 165-172.

Harper, S. R., Carini, R. M., Bridges B. K., \& Hayek, J. C. (2004). Gender difference in student engagement among African American undergraduates at historically Black colleges and universities. Journal of College Student Development, 45(3), 271-284.

James, S., Hartnett, S., \& Kalsbeek, W. (1983). John Henryism and blood pressure differences among black men. Journal of Behavioral Medicine, 6, 259-278.

June, L. N., Curry, B. P. \& Gear, C. L. (1990). An 11-year analysis of Black students' experience of problems and use of services: Implications for counseling professionals. Journal of Counseling Psychology, 37(2), 178-184.

Lazarus, R. S. (1966). Psychological stress and the coping process. New York: McGraw-Hill.

Lazarus, R. S., \& Cohen, J. B. (1977). Environmental stress. In I. Altman \& J. F. Wohlwill (Eds.). Human behaviors and environment (Vol. 2), New York: Plenum.

Lett, D. F., \& Wright, J. V. (2003). Psychological barriers associated with matriculation of African American students in predominately White institutions. Journal of Instructional Psychology, 30(2), 189-196.

Manning, P. K., \& Cullum-Swan, B. (1994). Narrative, content, and semiotic analysis. In N. K. Denzin \& Y. S. Lincoln (Eds.), Handbook of qualitative research (pp. 463-477). Thousand Oaks, CA: Sage.
Morgan, D. L., \& Krueger, R. A. (1998). The focus group kit. Thousand Oaks, CA: Sage.

Myers, H. (1993). Biopsychosocial perspective on depression in African-Americans. In Psychopharmacology and Psychobiology of Ethnicity, K. M. Lin, R.E. Poland, \& G. Nakasaki (Eds.). Washington, DC: American Psychiatric Press, Inc.

Ross, S. E., Niebling, B. C., \& Herkert, T. M. (1999). Sources of stress among college students. College Student Journal, 33(2), 312-317.

Rowser, J. F. (1997). Do African American students' perceptions of their needs have implications for retention? Journal of Black Studies, 27(5), 718-726.

Snowden, L. (2001). Barriers to effective mental health services for African Americans. Mental Health Services Research, 3(4), 181-187.

Stockdale, M. S. (2002). Analyzing focus group data with spreadsheets. American Journal of Health Studies, 18(1), 55-60.

Swallow, V., Newton, J., \& Lottum, C. V. (2003). How to manage and display qualitative data using 'Framework' and Microsoft ${ }^{\circledR}$ Excel. Journal of Clinical Nursing, 12, 610-612.

Thompson, C. E., Neville, H., Weathers, P. L., Poston, W. C., \& Atkinson, D. R. (1990). Cultural mistrust and racism reaction among African-American students. Journal of College Student Development, 31(2), 162-168.

Ulin, P. R., Robinson, E. T., \& Tolley, E. E. (2005). Qualitative methods in public health: A field guide for applied research. San Francisco, CA: Jossey-Bass.

U.S. Department of Health and Human Services. (1999). Mental health: A report of the Surgeon General. Rockville, MD: Office of the Surgeon General.

Walden, C. (1994). The health status of African American college students: A literature review. Journal of American College Health, 42(5), 199-205.

Western, B., Schiraldi, V., \& Ziedenberg, J. (2003) Education and incarceration. Washington, DC: Justice Policy Institute.

Williams, D. R. (2003). The health of men: Structured inequalities and opportunities. American Journal of Public Health, 93, 724-731. 